\title{
International Evidence on the Persistence of Economic Fluctuations
}

\section{Citation}

Campbell, John Y., and N. Gregory Mankiw. 1989. International evidence on the persistence of economic fluctuations. Journal of Monetary Economics 23(2): 319-333.

\section{Published Version}

http://dx.doi.org/10.1016/0304-3932(89)90054-8

\section{Permanent link}

http://nrs.harvard.edu/urn-3:HUL.InstRepos:3224417

\section{Terms of Use}

This article was downloaded from Harvard University's DASH repository, and is made available under the terms and conditions applicable to Other Posted Material, as set forth at http:// nrs.harvard.edu/urn-3:HUL.InstRepos:dash.current.terms-of-use\#LAA

\section{Share Your Story}

The Harvard community has made this article openly available.

Please share how this access benefits you. Submit a story.

\section{Accessibility}


NBER WORKING PAPER SERIES

\author{
INTERMATIONAL EVIDENCE \\ ON THE PERSISTENCE OF \\ ECONOMIC FLUCTUATIONS
}

John Y. Campbe11

N. Gregory Mankiw

Working Paper No. 2498

\author{
NATIONAL BUREAU OF ECONOMIC RESEARCH \\ 1050 Massachusetts Avenue \\ Cambridge, MA 02138 \\ January 1988
}

\begin{abstract}
We are grateful to Charles Plosser and an anonymous referee for helpful comments and to James Stock and Mark Watson for use of their programs. This work was supported by the National Science Foundation and the John $M$. Olin Fellowship at the NBER. The research reported here is part of the ABER's research program in Economic Fluctuations. Any opinions expressed are those of the authors and not those of the National Bureau of Economic Research.
\end{abstract}


NBER Working Paper 12498

January 1988

International Evidence on the Persistence of Economic Fluctuations

\section{ABSTRACT}

This paper presents new evidence on the persistence of fluctuations in real GNP. Two measures of persistence are estimated non-parametrically using post-war quarterly data from Canada, France, Germany, Italy, Japan, the United Kingdom, and the United States. These estimates are compared with Monte Carlo results from various $A R(2)$ processes. For six out of seven countries, the results indicate that a 1 percent shock to output should change the long-run univariate forecast of output by well over 1 percent. Low-order ARMA models for output growth are also estimated, and yield similar conclusions. Finally, the persistence in relative outputs of different countries is examined.

John Y. Campbell

Woodrow Wilson School

Princeton University

Princeton, NJ 08544
N. Gregory Mankiw National Bureau of Economic Research 1050 Massachusetts Ave. Cambridge, MA 02138 


\section{Introduction}

Since the provocative work of Nelson and Plosser (1982), much research has been devoted to the question of whether, and to what extent, fluctuations in real GNP are trend-reverting. In contrast to what was the prevailing view only a few years ago, it appears that shocks to real GNP do not dissipate in five or ten years. Indeed, it is hard to reject the view that real GNP is as persistent as a random walk with drift.

Most of the recent work addressing the persistence question has used data for the United States. Yet in post-war United States data, there are only eight non-overlapping five-year intervals. One would thus expect that such data can provide only an imprecise estimate of persistence. The monte Carlo experiments reported in Campbell and Mankiw (1987b) and be low in this paper indeed confirm that it is difficult to estimate persistence with such a small data set.

One strategy for obtaining more information about persistence is to expand the data set by using United States data from before the war. Nelson and Plosser use data beginning in 1909, and cochrane (1986) uses data beginning in 1869 . The primary problem with such an approach is that the older data may not be comparable to the newer data. In Campbell and Mankiw (1987a), we report that the persistence properties of the data from 1869 to 1930 are very different from the persistence properties of the data since 1930. Romer's (1987) recent re-examination of GNP data from before Wor ld War I indicates that there are serious deficiencies in the construction of the older data. Her results call into question the reliability of using pre-war data to estimate the persistence of economic fluctuations. 
A second strategy for obtaining more information on persistence, which is adopted by Stulz and wasserfallen (1985), Kormendi and McGuire (1987), and in this paper, is to expand the data set by using data from other countries. Here we examine data from Canada, France, Germany, Italy, Japan, the United Kingdom, and the United States. The estimate of persistence we obtain for every country other than the United Kingdom exceeds that for the United States. It is hard to reconcile the data from most of these countries with the view that fluctuations in output dissipate in five or ten years.

International data can also shed light on whether, as Lucas (1977) suggests, "all business cycles are alike." A stylized fact often noted about United States post-war quarterly data is that the first autocorrelation of the growth rate is positive (Blanchard 1981, Kydland and Prescott 1980). Here we show that this autocorrelation is larger for the United States than for any other country we study. In fact, for France, Germany, and the United Kingdom, the first autocorrelation of output growth is negative.

Section II of this paper defines more precisely what we mean by the "persistence" of economic fluctuations, while Section III discusses how these persistence measures can be estimated nonparametrically. Section IV presents some Monte Carlo results to shed light on the small sample properties of these estimators of persistence under different assumptions regarding the true stochastic process. Section $V$ describes the data, and Section $V I$ presents the single-country results. - Section VII examines the relative output of different countries. Section VIII concludes. 


\section{Iwo Concepts of Persistence}

What is persistence? for some purposes, a shock to an economy way be considered persistent if it lasts for more than one period. Here, however, we take persistence as meaning "continuing for a long tine into the future." More formally, suppose that the change in log of GNP is a stationary process with moving average representation

$$
\text { (1) } \Delta Y_{t}=A(L) \epsilon_{t}
$$

where $A(L)=1+A_{1} L+A_{2} L^{2}+A_{3} L^{3}+\ldots$ is an infinite polynomial in the lag operator, and $\epsilon_{t}$ is white noise. The impact of a shock in period $t$ on the growth rate in period $t+k$ is $A_{k}$. The impact of the shock on the level of GNP in period $t+k$ is therefore $1+A_{1}+\ldots+A_{k}$. The ultimate impact of the shock on the level of GNP equals the inf inite sum of these moving average coefficients, which is $A(1)$. The value of $A(1)$ is the measure of persistence we proposed in our previous paper (1987a). For a random walk, A(1) equals one for any series stationary around a deterministic trend, $A(1)$ equals zero.

Cochrane (1986) has recently proposed another measure of persistence, which has also been studied in Campbell and Mankiw (1987a) and Huizinga (1987). His measure can be written either as a ratio of variances or as a function of autocorrelations:

$$
v^{k}=\frac{1}{k+1} \frac{\operatorname{Var}\left(\gamma_{t+k+1}-\gamma_{t}\right)}{\operatorname{Var}\left(\gamma_{t+1}-\gamma_{t}\right)}=1+2 \sum_{j=1}^{k}\left(1-\frac{j}{k+1}\right) \rho_{j}
$$

where $\rho_{j}$ is the $j^{\text {th }}$ autocorrelation of $\Delta Y_{t}$ if $Y_{t}$ follows a randon walk. then the variance of the $(k+1)$-lagged difference is $(k+1)$ times the variance 
of the once-lagged difference. Hence, for a random walk, the above expression $v^{k}$ is one for all $k$. For any stationary series, the variance of the $(k+1)$-lagged difference approaches twice the variance of the series, which is a finite constant. Hence, for any stationary series, $v^{k}$ approaches zero for large $k$. The limit of the variance ratio is thus natural measure of persistence.

The limiting variance ratio, which we call $v$, is simple and intuitively appealing. Note that

$$
v=\lim _{k \rightarrow \infty} v^{k}=1+2 \sum_{j=1}^{\infty} \rho_{j}
$$

If a stochastic process reverts to deterministic time trend, then one would expect unusually low growth rates (recessions) to be followed by unusually high growth rates (recoveries). Thus, at some lags, one would expect negative autocorrelations. As equation (3) shows, trend reversion is captured by this weasure of persistence, since $v$ incorporates all of these autocorrelations.

The two concepts of persistence are closely related. For two simple and important cases -- a stationary process and a random walk -- the two measures of persistence $A(1)$ and $V$ produce the same number. More generally, however, the two measures are not exactly the same. Define $R^{2}=1-\operatorname{Var}(\epsilon) / \operatorname{Var}(\Delta Y)$. the fraction of the variance that is predictable from knowledge of the past history of the process. Then $A(1)$ can be expressed as

$$
A(1)=\sqrt{\frac{V}{1-R^{2}}}
$$

Equation (4) shows that the square root of Cochrane's measure of persistence is lower bound on $A(1)$. The more highly predictable is the differenced 
process, the greater is the disparity between the two measures.

\section{Estimating Persistence}

One can estimate the persistence measure $v$ very simply by replacing the population autocorrelations in equation (2) with the sample autocorrelations. The estimator is

$$
v^{k}-1+2{ }_{j=1}^{k}\left(1-\frac{j}{k+1}\right) \hat{\rho}_{j}
$$

As long as $k$ increases with the sample size, this estimator consistently est imates $\vee 2$

It is also possiole to compute nonparametrically an approximate estimate of $A(1)$, called $A^{k}(1)$, as

$$
A^{k}(1)=\sqrt{\frac{v^{k}}{1-p_{1}^{2}}}
$$

The estimate of $A(1)$ is computed by replacing the $R^{2}$ in equation (4) with the square of the first autocorrelation. since $\rho_{1}^{2}$ is an underestimate of $R^{2}$. except for an AR(1) process, this est imate tends to understate $A(1)$. In any given sample, it is of course necessary to choose $k$, the number of autocorrelations to include. Including too few autocorrelations may obscure trend reversion manifested in higher autocorrelations. Including too any autocorrelations may tend to find excessive trend reversion: as $k$ approaches the sample size $T$, the estimator approaches zero. Since the sample mean has been removed from the data, $v^{k}$ is identically zero at $k=T-1$. Hence, while large $k$ appears preferable, $k$ must be small relative to the sample size. 
For the case in which $\gamma_{t}$ is a randon walk with drift, the mean value of $\hat{v}^{k}$ is approximately $(T-k) / T$ rather than one (Campbell and Mankiw, $\left.1987 b\right)$. Therefore, to correct for this downward bias, we multiply $\vec{b}^{k}$ by $T /(T-k)$. A) though it reduces somewhat the comparability of these results with those in out previous papers, this bias correction makes the estimates easier to interpret.

\section{Monte Carlo Results}

This section presents some Monte Carlo results for the estimators of $A(1)$ and $V$ discussed above. The Monte Carlo experiment is designed to examine more precisely the choice of window size $(k)$ and to judge the ability of the estimates to distinguish between different stochastic processes.

The true process is assumed to be on AR(2) process:

$$
\left(1-r_{1} l\right)\left(1-r_{2} L\right) Y_{t}=\epsilon_{t}
$$

where $\epsilon_{t}$ is $N\left(0, \sigma^{2}\right)$ and $r_{1}$ and $r_{2}$ are the two roots of the process. If both $r_{1}$ and $r_{2}$ are less than one, then the process is stationary. If $r_{1}$ or $r_{2}$ equals one, then the process for $Y_{t}$ is integrated, that is, it is stationary only after differencing.

While the process in equation (1) does not include a trend in $Y$, the presence of such a trend would not affect the Monte Carlo results in any way. All the statistics we examine are computed frow the demeaned values of $\Delta Y$. Any deterministic trend in $Y$ would be eliminated when we subtract the sample mean.

For the larger root, we try values of $0.8,0.9,0.95$, and 1.0 . For the swaller root, we try values of $0.0 ; 0.25$, and 0.5 . We thus simulate twelve 
different AR(2) processes. To gauge the persistence of these various parameter combinations, we present in Table 1 the time impulse responses to a unit shock at horizons of 20,40 , and 80 quarters. Table 2 shows the first four population autocorrelations of changes in the processes, while Table 3 shows variance ratios $v^{k}$, computed as in the right hand side of equation (2) using population autocorrelations, for $k=20,40$, and 60 .

The autocorrelation patterns in Table 2 are of three different types. If the smaller root is 0.0 (so that the process is an AR(1) in levels), then all autocorrelations of the differenced process are negative or zero. If the larger root is 1.0 (so that the process is an AR(1) in differences), then all autocorrelations of the differenced process are positive or zero. If the smaller root is greater than 0.0 and the larger root is less than 1.0, then the lowest-order autocorrelations are positive and higher-order autocorrelations are negative. For these last processes the liviting variance ratio $V$ is zero but the variance ratio $v^{k}$ may approach $V$ quite slowly. for the process with roots $(0.95,0.5)$, for example, $v^{k}$ in Table 3 is 1.78 at $k$. 20. Clearly it would be hard to distinguish this process from anit root process even if one knew the true $v^{k}$ at $k=20,40$, or 60 .

In practice, of course, a further problem arises because we must estimate $v^{k}$ using $v^{k}$. To see what effect this has, we run a small Monte Carlo experiment. For each process, we simulate a sample and then compute the estimates of persistence. There are 500 replications, and each has 100 observations, which is a typical number of post-war quarterly observations we use below. Tables 4 and 5 report the means of the two persistence estimates for $k=20,40$, and 60 , as well as the standard deviations of the estimates. 
The results show how difficult it is to distinguish between different representations on the bas is of these nonparametric persistence estimates. For $k=40$, the mean estinate of $v$ is 1.02 for both a random walk and the stationary AR(2) with roots $(0.95,0.25)$. The associated standard deviations are substantial, but they are smaller for less persistent processes.

The finding that the standard deviation of $\hat{V}^{k}$ is smaller for less persistent processes has an important impication. It is easier to reject the hypothesis that a less persistent process generated a data set with high values of $\hat{v}^{k}$ than it is to reject the hypothesis that a more persistent process generated data set with low values of $\hat{v}^{k}$. For example, if we observe $\hat{v}^{k}=1.0$ for $k=40$, we can reject roots of $(0,9,0.25)$ at conventional significance levels. On the other hand, if we observe $\hat{v}^{k}=0.1$ for $k=40$, we cannot reject roots of $(1.0,0.5)$.

\section{v. The Data}

We examine quarterly data from seven major countries: Canada, France, Germany, Italy, Japan, the United Kingdom, and the United States. These countries make up the "Group of Seven" (G7) which meets periodically to coordinate macroeconomic policy. All the data are taken from the data banks aintained by Data Resources, Inc., which obtains the data originally fron the International Monetary fund's International Financial statistics. ${ }^{3}$

For each country, use real Gross National Product (GNP) or real Gross Domestic Product (GDP), whichever is supplied by the International Monetary Fund. In those cases in which both nowinal GNP and nominal GDP are available, we comared the two.real. series under the assumption of common. 
deflator. The difference in results was extremely minor. He concluded that for our purposes, the differences between GNP and GDP are not iaportant.

In each case, we used the longest series of quarterly data available in this data bank. The sample periods are:

Country

Canada (GNP)
France (GOP)
Germany (GNP)
Italy (GDP)
Japan (GNP)
U.K. (GDP)
U.S. (GNP)

\section{Sample}

$$
\begin{aligned}
& 57: 1-86: 2 \\
& 65: 1-86: 2 \\
& 60: 1-86: 2 \\
& 60: 1-85: 1 \\
& 57: 1-86: 2 \\
& 57: 1-86: 2 \\
& 57: 1-86: 3
\end{aligned}
$$

Number of Observations

$$
\begin{array}{r}
118 \\
85 \\
106 \\
101 \\
118 \\
118 \\
119
\end{array}
$$

Alt the data, except that for the United Kingdom, are seasonally adjusted. To make the U.K. data comparable to the other data, we seasonally adjusted them using the $x-11$ program used to adjust $U . S$ data. (The prograw is that available in EPS by Data Resources, Inc.) The persistence estimates for Britain using data adjusted by $x-11$ were largely the same as those obtained with the unadjusted data and with data adjusted by seasonal dumies.

\section{Single Country Results}

In this section we examine the persistence properties of the data from our seven countries, considered separately. In Table 6 we present the first 16 autocorrelations of the change in log real output for each of the countries. The top half of Table 7 reports the persistence est imates $\mathrm{V}^{k}$ and $A^{k}(1)$ for window sizes $k=20,40$, and 60 .

The results for the United States, in the right-hand column of each table, are similar to those reported in Campoell and Mankiw (1987a, 1987b).4 The first autocorrelation of U.S. output growth is 0.3 , subsequent 
autocorrelations die off rapidly, and there is string of small negative correlations between lags 4 and 9 . The persistence measures $v^{k}$ for the $v . s$. fall frow 1.11 with $k=20$, to 0.70 with $k=60$. Comparing the first few autocorrelations with the numbers in Table 2, they appear consistent with roots of $(1.0,0.25),(0.95,0.25),(0.95,0.5)$ or even $(0.9,0.5)$ for U.S. output. Comparing the persistence measures in Table 7 with the Monte Carlo results in Tables and 5 , the same combinations of roots appear to be consistent with the data. These results indicate once again how hard it is to distinguish a process with permanent shocks from one with shocks which die out slowly.

The results for other countries are less ambiguous than those for the United States. With the exception of the United Kingdom, all the other countries have persistence measures at $k=40$ and $k=60$ that are higher than the U.S. measures, and higher than any of the stationary $A R(2)$ processes we simulate. In fact, at $k=60$ the $\hat{v}^{k}$ measures for these countries are all higher than any of the processes we simulate, including the highly persistent processes with a unit root. These results are not due to very large positive low-order autocorrelations, since Canada, Italy and Japan have small positive first autocorrelations, and France and Germany actually have negative first autocorrelations. Rather, the persistence of fluctuations in these countries is due to the absence of many small negative autocorrelations in output growth. 5

The exception to the pattern of persistence is the United Kingdom. The first five autocorrelations of British output growth are all negative; and the persistence measures are less than one. These results are robust to the 
method used to deseasonalize the British data. The British results suggest a process such as an $A R(2)$ with roots of $(0.9,0.25)$ or $(0.95 .0)$. Yet the results are consistent with substantial persistence since our Monte Carlo study showed very large standard deviations of $v^{k}$ for persistent processes. The U.K. est imates are less than one standard deviation below the wean estimates for a random walk. 6

As a check on the robustness of our results, we also estimated ARMA models for output growth in each country. We repeated the procedures of Campoel1 and Mankiw (1987a), omitting the U.S.7 We used an exact maximus likelihood procedure to estimate models with up to 2 autoregressive and 2 moving average parameters, and for each model we computed the impulse response function at a horizon of 80 quarters. This is an estimate of the persistance measure $A(1)$. We also calculated the value of the Akaike Criterion for each model this is one possible way to choose a "best" ARMA representation.

The ARMA results are fully consistent with the nonparametric results on persistence, In Canada, the likelihood function is rather flat, the Akaike Criterion picks an AR(1) model for output growth, with an $A(1)$ value of 1.15 . but all the other estimated models give similar persistence estimates. In France, the Akaike Criterion picks the ARMA $(1,2)$ mode 1 . This and the ARMA (2.2) have considerably higher likel ihoods than the lower-order aodels. The They give $A(1)$ estimates of 1.65 and 1.71 respectively, while the lower-order models estimate $A(1)$ to be less than unity. In Germany, the ARma(2,2) has a much higher likelihood than any lower-order model, and it estimates A(1) at 1.00; the lower-order models deliver simflar persistence estimates. In Italy. 
the likelihood function is again quite flat. The Akaike Criterion picks an AR (1) model, but the ARMA $(2,2)$ is nearly as good. All the estimated models have A(1) values of between 1.14 and 1.32. In Japan, the Akaike Criterion picks the ARMA(1,2) mode1, with an A(1) estimate of 3,67. The ARMA $(1,1)$, ARMA $(2,1)$ and $\operatorname{ARMA}(2,2)$ models have similar likelihoods and similar persistence estimates. Finally, in the U.K. the Akaike Criterion picks an MA(1) model with a persistence estimate of 0.82 . The higher-order models give lower persistence estimates, and the $\operatorname{ARMA}(1,2)$ and $\operatorname{ARMA}(2,2)$ mode is est imate the impulse response at 80 quarters to be as low as 0.06 .

In principle, as Cochrane (1986) has pointed out, it is possible for low-order ARMA models and nonparametric methods to give very different persistence estimates. In practice, we have found that this is not the case. For every country we study, except the United Kingdom, both nonparametric and ARMA estimates of persistence exceed unity, while in the U.K. both estimates of persistence are smal1.

Table $B$ presents non-parametric bias-corrected persistence estimates for two subsamples. We split the period in 1972:4, approximately the time of the worldwide productivity slowdown. These figures tell a far less consistent story. For example, prior to 1973, fluctuations in Canada seem highly persistent while those in France seem transitory. After 1973, fluctuations in Canada appear to become transitory while those in France become persistent. These results are difficult to interpret in part because persistence is not well estimated with such short"time series. Moreover, the break point in 1972 is implicitly based on the data, which affects the statistical properties of the estimator in unknown ways. 
The results in Table 8 suggest the possibility that there was change in the mean growth rate and that failing to account for this change biases the previous persistence estimates. In each country, the mean grouth rate fell in the second subsample, typically by 0.6 percent per quarter. Estimating persistence in the presence of non-linear deterministic trends is a potential topic for future research.

\section{Cross-Country Results.}

In the previous section, we found considerable persistence in real output fluctuations for six out of seven countries. An interesting further question is whether fluctuations in relative real output (defined as the difference in log real output between one country and another) are also persistent. It is entirely possible that they are not, that when one country grows particularly fast relative to another this good fortune tends to be reversed subsequently. In the extreme, relative real output for some countries might be stationary around a fixed mean or trend; such countries would have cointegrated real output processes with a cointegrating vector of $(1-1)$ (Engle and Granger (1987)).

In Table 9 we compute bias-corrected persistence measures for relative real output for each pair of countries in our sample. To conserve space, we report results only for a window size $k=40$, results for $k=20$ and 60 are similar. The bottom left part of the table gives bias-corrected- ${ }^{k}$, while the top right of the table gives bias-corrected $A^{k}(1)$.

Some of the results in Table 9 could be predicted from the single-country results. British output fluctuations are highly transitory and Japanese 
fluctuations are highly persistent. It is not surprising that these properties carry over when fluctuations are measured relative to other countries output. A striking new result in Table 9, however, is that Canada, France, Germany and Italy form a group whose relative output fluctuations are transitory, even though their absolute output fluctuations are persistent. The bias-corrected $\hat{v}^{k}$ stat istics for relative output within this group never exceed 0.46 , while the equivalent statistics for absolute output are all larger than 2.13. Real output in the United States moves more independently; U.S. fluctuations relative to other countries are generally about as persistent as fluctuations in U.S. output itself.

Even though fluctuations in relative real output are quite transitory for some countries, there is no strong evidence that relative real output is stationary for any pair of countries. Dickey-Fuller tests with an autoregressive correction of order 1 through 4 fail to reject the null hypothesis that relative real output levels for Canada, France, Germany and Italy have unit root. The tests proposed by Stock and Watson (1987), which allow arbitrary linear combinations of different countries" outputs to be stationary, also fail to find evidence that there are any stationary combinations. 8

\section{Conclusion}

In Campbell and Mank iw (1987a), we confirmed the resuit in Nelson and Plosser (1982) that fluctuations in U.S. output appear highly persistent. A one percent shock to output should change the univariate forecast of output by over one percent over ny foreseeable horizon. Here we have examined data 
from six other countries. With the sole exception of the United Kingdom, output appears more persistent in these other countries.

We find persistence in six out of seven countries despite the fact that there are substantial differences across countries in the individual autocorrelations of output growth. The first autocorrelation, for exanple, ranges from 0.30 in the U.S. to -0.38 in France, while the second ranges from 0.19 in the U.S. to -0.07 in Germany. Because of these differences, we have not tried to pool data from different countries by assuming that they are generated by a single underlying stochastic process. We have studied the behavior of relative output (the difference in log output across countries). and have found some evidence that relative output levels for Canada, France, Germany, and Italy are less persistent than the levels of output of these countries considered in isolation.

Our results shed some light on different strategies which have been suggested for est imating persistence. In Campbell and Mankiw (1987a), we modeled the change in log output as a stationary ARMa process, estimated the parameters of this process using exact maximum likelihood, and then inferred persistence from the estimated parameters. 9 Here we have adopted the non-parametric approach suggested by Cochrane (1986).

There are several advantages to the non-parametric approach. First, the results are obviously not dependent on a particular parameterization. Second, it is clear which sample moments drive the estimates. Third, the est imator is computationally simple. The advantages of this approach thus appear substantial.

One purpose of this paper has been to examine this approach more closely using Monte Carlo techniques. We have shown that the simplest non-parametric 
estimator of persistence can suffer from severe downward bias; this can be approximately eliminated for the case of a random walk process by a sample degrees of freedon correction. We have also shown that highly persistent processes can generate data that do not appear persistent, but that transitory processes are much less likely to generate apparently persistent data.

Future work ight attempt to examine more systematically the pros and cons of the different approaches. It is reasonable to conjecture that the parametric approach yields more efficient estimates of persistence if the parameterization is correct, but yields inconsistent estimates if the parameterization is incorrect. For the data examined here, the estimates of persistence obtained in practice with the non-parametric approach are similar.. to those obtained with the parametric ARMA approach. This finding suggests that simple ARMA nodels well approximate GNP data for these seven countries. 


\section{Footnotes}

1. We compute the $j^{\text {th }}$ autocovariance as the sum of the $t-j$ cross products divided by $T-j$. This computation does not guarantee that $v^{k}$ is positive. Dividing the $T-j$ cross-products by $T$ would guarantee a positive estimate. In practice, as long as $k$ is small relative to $T$, the difference is not important.

2. The estimator $\hat{v}^{k}$ can be interpreted in terms of the frequency domain. As Priestley (1982, p. 463) shows, $\hat{v}^{k}$ is the estimate of the normalized spectral density at frequency zero that uses a "Bartlett window." A result in spectral analysis gives the asymptotic standard error of $\hat{v}^{k}$ as

$$
\text { s.e. }\left[v^{k}\right]=\frac{\hat{v}^{k}}{\sqrt{\frac{3}{4} \frac{T}{(k+1)}}}
$$

where $T$ is the sample size. Monte Carlo results, however, lead us to be skeptical about the usefulness of this standard error in samples of typical size. See also Lo and Mackinlay (1987).

3. The International financial Statistics contain quarterly national income accounts data for relatively few countries, and these data are of ten available for only a short period. We include all the major countries for which data are available.

4. Small differences are due to the shorter sample period of this paper.

5. The most extreme case is Japan. Here the autocorrelations show no tendency to die away to zero, suggesting that Japanese output growth way have 
a unit root. This would be an extreme for of persistence. Dickey-fuller tests with autoregressive corrections of order 0 through 'reject at the $1 \%$ level the null hypothesis that Japanese output growth has a unit root las it also does for the other countries in our sample); however. Schwert (1987) has shown in a Monte Carlo study that unit root tests are biased towards false rejection when the data are generated by an integrated ARMA process with a large moving average root. This problem may affecting the Dickey-fuller test for Japanese output growth.

6. Stockman (1987) also finds that U.K. output is less persistent than that of other European countries. We note that even for the U.K. there is no clear evidence that output is stationary around a determistic level. Dickey-fuller tests with autoregressive corrections of order o through 4 fail to reject at even the $10 \%$ level the null hypothesis that the level of U.K. real GDP has a unit root.

7. Detailed ARMA results for the U.S. are reported in CampDell and Mankiw (1987a).

B. This result holds whether we carry out the tests using data from all seven countries, from a group of six excluding Japan, from a group of five excluding Japan and the U.K., or from a group of four excluding Japan, the U.K., and the U.S.

9. Another approach to estimating perststence is the use of unobserved components models (e.g., Watson, 1986; Clark, 1987). As discussed in Campbell and Mankiw (19870), these models can be viewed as imposing 
restrictions on ARMA models. In this sense, the unobserved components models are the most parametric. Without strong reasons to believe these restrictions a priori, however, a less strict parameterization appears preferable. 


\section{References}

Blanchard, 0livier J., 1981. "What is Left of the Multiplier-Accelerator" American Economic Review Papers and Proceedings $71: 150-154$.

Campbe11, John Y. and N. Gregory Mankiw, 1987a. "Are Output Fiuctuations Transitory?" Quarterly Journal of Economics, November: 857-880. and - 1987b. "Permanent and Transitory Components in

Macroeconomic Fluctuations," American Economic Review Papers and Proceedings, $77: 111-117$.

Clark, Peter K., 1987. "The Cyclical Component of U.S. Economic Activity," Quarterly Journal of Economics, November.

Cochrane, John H., 1986. "How Big is the Randon walk in GNP?" unpublished paper. University of Chicago.

Dickey, Dayid A. and Wayne A. "Lller. 1981. "Likelihood Ratio statistics for Autoregressive Time Series with a Unit Root," Econometrica 49:1057-72.

Engle, Robert F. and Clive 4.3 . Granger, 2987. "Cointegration and Error-Correction: Representation, Estimation and Testing," Econometrica $55: 251-76$.

Huizinga, John, 1987. "An Empirical Investigation of the Long-Run Behavior of Real Exchange Rates," Carnegie-Rochester Conference Series on Public Policy, $27: 149-214$.

Kormendi, Roger C. and Philip McGuire, 1983. "The Nonstationarity of Aggregate Output: A Multi-Country Perspective," unpublished paper. University of Michigan. 
Kydland, Finn E., and Edward C. Prescott, 1980. "A Competitive Theory of Fluctuations and the Feasibility and Desirability of Stabilization Policy." in S. Fischer, ed. Rational Expectations and Economic Policy. Chicago: University of Chicago Press.

Lo, Andrew W. and A. Craig Mackinlay, 1987. "A Simple Specification Test of the Random Walk Hypothesis," unpublished paper, Wharton School, U. Penn. Lucas, Rodert E., Jr., 1977. "Understanding Business Cycles," CarnegieRochester Conferences on Public Policy, 5:7-29.

Nelson, Charles R. and Charles I. Plosser, 1982. "Trends and Random Walks in Macroeconomic Time Series," Journal of Monetary Economics 10:139-62.

Priestley, Maurice B., 1982. Spectral Analysis and Time Series. London: Academic Press.

Romer, Christina, 1986. "The Prewar Business Cycle Reconsidered, Hew Estimates of Gross National Product, 2869-1918." NBER Working Paper No. 1969. Cambridge, MA: National Bureau of Economic Research. Schwert, 6. William, 1987. "Tests for Unit Roots: A Monte Carlo Investigat ion," unpublished paper, University of Rochester.

Stock, James H. and Mark W. Watson, 1987. "Testing for Common Trends," Hoover Institution Working Paper E-87-2.

Stockman, Alan, 1987. "Sectoral and National Aggregate Disturbances to Industrial Output in Seven European Countries," unpublished paper. University of Rochester. 
Stulz, Rene and walter Wasserfallen, 1985. "Macroconomic Time-Series, Business cycles, and Macroeconomic Policies," Carnegie-Rochester Conference on Public Policy 22:9-54.

Watson, Mark W., 1986. "Univariate Detrending Methods with Stochastic Trends," Journal of Monetary Economics 18:1-27. 
Table 1

True Impulse Responses for Various AR(2). Processes at $t=20,40$, and 80

\section{Larger Root}

\begin{tabular}{|c|c|c|c|c|c|}
\hline \multirow[b]{2}{*}{ Smaller } & \multirow[b]{2}{*}{ Root } & \multirow[t]{2}{*}{0.8} & \multirow[t]{2}{*}{0.9} & \multirow[t]{2}{*}{0.95} & \multirow[t]{2}{*}{1.0} \\
\hline & & & & & \\
\hline & 0.0 & 0.01 & 0.12 & 0.36 & 1.00 \\
\hline & & 0.00 & 0.02 & 0.13 & 1.00 \\
\hline & & 0.00 & 0.00 & 0.05 & 1.00 \\
\hline & 0.25 & 0.02 & 0.17 & 0.49 & 1.33 \\
\hline & & 0.00 & 0.02 & 0.17 & 1.33 \\
\hline & & 0.00 & 0.00 & 0.06 & 1.33 \\
\hline & 0.5 & 0.03 & 0.27 & 0.76 & 2.00 \\
\hline & & 0.00 & 0.03 & 0.27 & 2.00 \\
\hline & & 0.00 & 0.00 & 0.10 & 2.00 \\
\hline
\end{tabular}

Note: This table presents the impulse response functions at 20 quarters, at 40 quarters, and at 80 quarters, for the AR(2) processes we simulate below. 
Table 2

Autocorrelations of Changes for Various AR(2) Processes

\section{Larger Root}

\begin{tabular}{|c|c|c|c|c|c|}
\hline \multirow{2}{*}{\multicolumn{2}{|c|}{ Smaller Root }} & \multirow[t]{2}{*}{0.8} & \multirow[t]{2}{*}{0.9} & \multirow[t]{2}{*}{0.95} & \multirow[t]{2}{*}{1.0} \\
\hline & & & & & \\
\hline & 0.0 & -0.10 & -0.05 & -0.03 & 0.00 \\
\hline & & -0.08 & -0.05 & -0.02 & 0.00 \\
\hline & & -0.06 & -0.04 & -0.02 & 0.00 \\
\hline & & -0.05 & -0.04 & -0.02 & 0.00 \\
\hline & 0.25 & 0.13 & 0.19 & 0.22 & 0.25 \\
\hline & & -0.07 & -0.01 & 0.03 & 0.06 \\
\hline & & -0.10 & -0.05 & -0.02 & 0.02 \\
\hline & & -0.09 & -0.06 & -0.03 & 0.00 \\
\hline & 0.5 & 0.35 & 0.43 & 0.46 & 0.50 \\
\hline & & 0.06 & 0.15 & 0.20 & 0.25 \\
\hline & & -0.07 & 0.01 & 0.06 & 0.13 \\
\hline & & -0.11 & -0.05 & -0.00 & 0.06 \\
\hline
\end{tabular}

Note: This table presents the first four autocorrelations of the AR(2) processes we simulate below. 
Table 3

True Variance Ratios for Various AR (2) Processes

\section{Larger Root}

\begin{tabular}{|c|c|c|c|c|}
\hline & 0.8 & 0.9 & 0.95 & 1.0 \\
\hline \multicolumn{5}{|l|}{ Smaller Root } \\
\hline \multirow[t]{3}{*}{0.0} & 0.24 & 0.42 & 0.63 & 1.00 \\
\hline & 0.12 & 0.24 & 0.43 & 1.00 \\
\hline & 0.08 & 0.16 & 0.31 & 1.00 \\
\hline \multirow[t]{3}{*}{0.25} & 0.38 & 0.69 & 1.02 & 1.62 \\
\hline & 0.20 & 0.39 & 0.70 & 1.65 \\
\hline & 0.13 & 0.27 & 0.52 & 1.65 \\
\hline \multirow[t]{3}{*}{0.5} & 0.66 & 1.21 & 1.78 & 2.81 \\
\hline & 0.34 & 0.70 & 1.25 & 2.90 \\
\hline & 0.23 & 0.48 & 0.92 & 2.93 \\
\hline
\end{tabular}

Note: This table presents variance ratios, measured as weighted sums of autocorrelations,

$v^{k}=\sum_{j=1}^{k}(1-j /(k+1)) \rho_{j}$, for $k=20,40$, and 60 , for the AR(2) processes wo simulate below.

These sums are persistence measures that use population autocorrelations rather than sample autocorrelations. 
Table 4

Results of Monte Carlo: Bias-Corrected $\mathrm{y}^{k}$

$k=20$

Larger Root

\begin{tabular}{|c|c|c|c|c|c|}
\hline \multirow{2}{*}{\multicolumn{2}{|c|}{ Smal ler Root }} & 0.8 & 0.9 & 0.95 & 1.0 \\
\hline & & & & & \\
\hline & 0.0 & $\begin{array}{c}0.30 \\
(0.11)\end{array}$ & $\begin{array}{c}0.51 \\
(0.24)\end{array}$ & $\begin{array}{c}0.76 \\
(0.38)\end{array}$ & $\begin{array}{c}0.99 \\
(0.54)\end{array}$ \\
\hline & 0.25 & $\begin{array}{c}0.46 \\
(0.21)\end{array}$ & $\begin{array}{c}0.80 \\
(0.39)\end{array}$ & $\begin{array}{c}1.23 \\
(0.64)\end{array}$ & $\begin{array}{c}1.66 \\
(0.91)\end{array}$ \\
\hline & 0.5 & $\begin{array}{c}0.83 \\
(0.38)\end{array}$ & $\begin{array}{c}1.43 \\
(0.65)\end{array}$ & $\begin{array}{c}2.13 \\
(1.04)\end{array}$ & $\begin{array}{c}2.66 \\
(1.35)\end{array}$ \\
\hline
\end{tabular}

$\underline{k}=40$

\section{Larger Root}

\begin{tabular}{|c|c|c|c|c|c|}
\hline \multirow{2}{*}{\multicolumn{2}{|c|}{ Smaller Root }} & 0.8 & 0.9 & 0.95 & 1.0 \\
\hline & & & & & \\
\hline & 0.0 & $\begin{array}{c}0.20 \\
(0.12)\end{array}$ & $\begin{array}{c}0.38 \\
(0.27)\end{array}$ & $\begin{array}{c}0.65 \\
(0.47)\end{array}$ & $\begin{array}{c}1.02 \\
(0.87)\end{array}$ \\
\hline & 0.25 & $\begin{array}{c}0.32 \\
(0.18)\end{array}$ & $\begin{array}{c}0.57 \\
(0.40)\end{array}$ & $\begin{array}{c}1.02 \\
(0.83)\end{array}$ & $\begin{array}{c}1.72 \\
(1.42)\end{array}$ \\
\hline & 0.5 & $\begin{array}{c}0.55 \\
(0.37)\end{array}$ & $\begin{array}{c}1.05 \\
(0.73)\end{array}$ & $\begin{array}{c}1.72 \\
(1.28)\end{array}$ & $\begin{array}{c}2.67 \\
(2.15)\end{array}$ \\
\hline
\end{tabular}

$\underline{k}=60$

\section{Larger Root}

\begin{tabular}{|c|c|c|c|c|}
\hline \multirow[b]{2}{*}{ Smaller Root } & 0.8 & 0.9 & 0.95 & 1.0 \\
\hline & & & & \\
\hline 0.0 & $\begin{array}{c}0.18 \\
(0.15)\end{array}$ & $\begin{array}{c}0.35 \\
(0.35)\end{array}$ & $\begin{array}{c}0.60 \\
(0.58)\end{array}$ & $\begin{array}{c}1.03 \\
(1.15)\end{array}$ \\
\hline 0.25 & $\begin{array}{c}0.28 \\
(0.23)\end{array}$ & $\begin{array}{c}0.50 \\
(0.50)\end{array}$ & $\begin{array}{c}0.95 \\
(1.05)\end{array}$ & $\begin{array}{c}1.73 \\
(1.90)\end{array}$ \\
\hline 0.5 & $\begin{array}{c}0.50 \\
(0.43)\end{array}$ & $\begin{array}{c}0.93 \\
(0.85)\end{array}$ & $\begin{array}{c}1.5 \mathrm{~B} \\
(1.55)\end{array}$ & $\begin{array}{c}2.55 \\
(2.70)\end{array}$ \\
\hline
\end{tabular}

Note: This table presents the results of a Monte Carlo experiment. It displays the mean of the persistence estimate and, in parentheses, the standard deviation of the estimates. These results are based on a sample of 100 and 500 replications. 
Table 5

Results of Monte Car lo Experiment: Bias-corrected $A^{k}(1)$ $k=20$

\section{Larger Root}

\begin{tabular}{|c|c|c|c|c|}
\hline \multirow[b]{2}{*}{ Smaller Root } & 0.8 & 0.9 & 0.95 & 1.0 \\
\hline & & & & \\
\hline 0.0 & $\begin{array}{c}0.55 \\
(0.10)\end{array}$ & $\begin{array}{c}0.70 \\
(0.16)\end{array}$ & $\begin{array}{l}0.85 \\
(0.21)\end{array}$ & $\begin{array}{c}0.96 \\
(0.26)\end{array}$ \\
\hline 0.25 & $\begin{array}{c}0.68 \\
(0.15)\end{array}$ & $\begin{array}{c}0.89 \\
(0.22)\end{array}$ & $\begin{array}{c}1.11 \\
(0.29)\end{array}$ & $\begin{array}{c}1.30 \\
(0.37)\end{array}$ \\
\hline 0.5 & $\begin{array}{c}0.95 \\
(0.22)\end{array}$ & $\begin{array}{c}1.30 \\
(0.31)\end{array}$ & $\begin{array}{c}1.61 \\
(0.44)\end{array}$ & $\begin{array}{c}1.82 \\
(0.50)\end{array}$ \\
\hline
\end{tabular}

$k=40$

\section{Larger Root}

\begin{tabular}{cccccc} 
& & 0.8 & 0.9 & 0.95 & 1.0 \\
\cline { 3 - 5 } & & & & & \\
& 0.0 & & & & \\
& & 0.43 & 0.59 & 0.76 & 0.94 \\
& 0.25 & $(0.12)$ & $(0.19)$ & $(0.28)$ & $(0.39)$ \\
& 0.54 & 0.72 & 0.97 & 1.25 \\
& 0.5 & $(0.17)$ & $(0.26)$ & $(0.39)$ & $(0.54)$ \\
& 0.76 & 1.07 & 1.39 & 1.74 \\
& $(0.26)$ & $(0.37)$ & $(0.56)$ & $(2.03)$
\end{tabular}

$k=60$

\section{Larger Root}

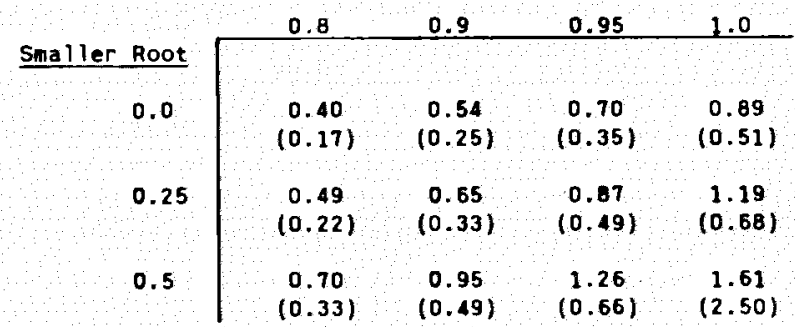

Note: This table presents the results of a Monte Carlo experiment. It displays the mean of the persistence estimate and, in parentheses, the standard deviation of the estimates. These. results are based on sample of 100 and 500 replications. 
Table 6

Autocorrelations of the Change in Log Real output

\begin{tabular}{|c|c|c|c|c|c|c|c|c|}
\hline & & $\begin{array}{r}\text { Canada } \\
\text { (GNP) }\end{array}$ & $\begin{array}{r}\text { France } \\
\text { (GDP) }\end{array}$ & $\begin{array}{c}\text { Germany } \\
\text { (GNP) }\end{array}$ & $\begin{array}{l}\text { Italy } \\
\text { (GDP) }\end{array}$ & $\begin{array}{l}\text { Japan } \\
\text { (GNP) }\end{array}$ & $\begin{array}{l}\text { U.K. } \\
\text { (GDP) }\end{array}$ & $\begin{array}{l}\text { U.S. } \\
\text { (GNP) }\end{array}$ \\
\hline$\underline{\mathrm{Lag}}$ & & & & & & & & \\
\hline 1 & & 0.13 & -0.38 & -0.07 & 0.16 & 0.07 & -0.17 & 0.30 \\
\hline 2 & & 0.08 & 0.11 & -0.07 & 0.09 & 0.17 & -0.01 & 0.19 \\
\hline 3 & & 0.15 & 0.16 & 0.11 & 0.08 & 0.26 & -0.04 & 0.00 \\
\hline 4 & & -0.12 & -0.04 & 0.18 & 0.01 & 0.19 & -0.03 & -0.03 \\
\hline 5 & & 0.10 & 0.02 & -0.19 & -0.08 & 0.18 & $-0 . D 0$ & -0.11 \\
\hline 6 & & -0.09 & 0.14 & 0.10 & -0.15 & 0.10 & 0.17 & -0.02 \\
\hline 7 & & -0.05 & 0.02 & 0.08 & 0.06 & 0.22 & 0.00 & -0.06 \\
\hline 8 & & 0.12 & -0.01 & -0.21 & 0.02 & 0.04 & 0.21 & -0.17 \\
\hline 9 & & 0.08 & 0.11 & -0.05 & 0.06 & 0.32 & -0.05 & -0.10 \\
\hline 10 & & 0.25 & 0.07 & 0.11 & 0.01 & 0.15 & -0.06 & 0.06 \\
\hline 11 & & -0.04 & 0.05 & -0.08 & 0.13 & 0.16 & 0.02 & 0.06 \\
\hline 12 & & 0.07 & -0.01 & -0.07 & 0.01 & 0.16 & -0.02 & -0.03 \\
\hline 13 & & 0.17 & 0.08 & 0.13 & 0.07 & 0.14 & 0.06 & -0.03 \\
\hline 14 & & -0.12 & 0.02 & 0.03 & 0.08 & 0.31 & -0.04 & -0.11 \\
\hline 15 & & 0.02 & 0.02 & 0.07 & -0.08 & 0.09 & 0.17 & -0.19 \\
\hline 16 & & -0.03 & 0.06 & -0.02 & -0.04 & 0.18 & -0.25 & -0.03 \\
\hline
\end{tabular}


Table 7

Estimates of Persistence in Log Real Output

\begin{tabular}{|c|c|c|c|c|c|c|c|}
\hline & Canada & France & Germany & Italy & Japan & U.K. & U.S. \\
\hline \multicolumn{8}{|c|}{ Bias-Corrected $v^{k}$} \\
\hline$k=20$ & 2.41 & 1.65 & 1.27 & 2.01 & 5.31 & 0.56 & 1.34 \\
\hline$k=40$ & 3.49 & 2.96 & 2.13 & 3.74 & 10.05 & 0.74 & 1.35 \\
\hline$k=60$ & 3.62 & 3.64 & 2.80 & 5.85 & 13.71 & 0.85 & 1.42 \\
\hline \multicolumn{8}{|c|}{ Bias-Corrected A $^{k}(1)$} \\
\hline$k=20$ & 1.57 & 1.39 & 1.13 & 1.44 & 2.31 & 0.76 & 1.21 \\
\hline$k=40$ & 1.88 & 1.86 & 1.46 & 1.96 & 3.18 & 0.88 & 1.22 \\
\hline$k=60$ & 1.92 & 2.06 & 1.68 & 2.45 & 3.71 & 0.94 & 1.25 \\
\hline
\end{tabular}


Table 8

Estimates of Persistence in Log Real Output: Subsamples

\begin{tabular}{|c|c|c|c|c|c|c|c|}
\hline & Canada & France & Germany & Italy & Japan & U.K. & U.S. \\
\hline \multicolumn{8}{|c|}{ START $-1972: 4$} \\
\hline \multicolumn{8}{|c|}{ Bias-Corrected $\hat{v}^{k}$} \\
\hline$k=10$ & 2.00 & 0.21 & 0.50 & 1.01 & 0.87 & 0.35 & 1.52 \\
\hline$k=20$ & 1.50 & 0.23 & 0.10 & 0.25 & 0.92 & 0.27 & 1.80 \\
\hline$k=30$ & 1.64 & 0.00 & 0.12 & 0.26 & 0.88 & 0.17 & 1.30 \\
\hline
\end{tabular}

Bias-Corrected $A^{-k}(1)$

\begin{tabular}{llllllll}
$k-10$ & 1.05 & 0.56 & 0.72 & 1.01 & 0.95 & 0.64 & 1.26 \\
$k=20$ & 1.27 & 0.59 & 0.33 & 0.51 & 0.97 & 0.56 & 1.38 \\
$k=30$ & 1.29 & 0.00 & 0.35 & 0.51 & 0.96 & 0.44 & 1.27 \\
\hline
\end{tabular}

1973 : 1-END

Bias-Corrected $\hat{v}^{k}$

$\begin{array}{rrrrrrrr}k=10 & 1.24 & 1.47 & 1.24 & 0.98 & 1.81 & 1.21 & 2.12 \\ k=20 & 0.78 & 1.48 & -0.63 & 0.81 & 1.75 & 0.68 & 0.71 \\ k=30 & 0.30 & 1.59 & -0.20 & 1.03 & 1.30 & 0.58 & -0.04\end{array}$

Bias-Corrected $\hat{A}^{k}(1)$

\begin{tabular}{rrrrrrrr}
$k=10$ & 1.21 & 1.22 & 1.08 & 1.07 & 1.35 & 1.11 & 1.55 \\
$k=20$ & 0.96 & 1.48 & 0.80 & 0.97 & 1.32 & 0.83 & 0.90 \\
$k=30$ & 0.60 & 1.59 & N/A & 1.09 & 1.14 & 0.77 & N/A \\
\hline
\end{tabular}




\section{Table 9}

Estimates of Persistence in Log Relative Real Output

\begin{tabular}{|c|c|c|c|c|c|c|c|}
\hline & Canada & France & Germany & Italy & Japan & U.K. & U.S. \\
\hline Canada & -2 & 0.52 & 0.41 & 0.41 & 1.92 & 0.77 & 1.50 \\
\hline France & 0.23 & -- & 0.62 & 0.52 & 1.77 & 1.00 & 1.21 \\
\hline Germany & 0.16 & 0.29 & $\ldots$ & 0.71 & 2.17 & 0.50 & 0.91 \\
\hline Italy & 0.17 & 0.22 & 0.46 & $\cdots$ & 1.45 & 0.84 & 1.24 \\
\hline Japan & 3.67 & 2.98 & 4.70 & 2.10 & - & 2.15 & 2.54 \\
\hline U.K. & 0.57 & 0.96 & 0.23 & 0.69 & 4.63 & -- & 0.38 \\
\hline U.S. & 2.26 & 1.39 & 0.81 & 1.53 & 6.37 & 0.14 & $\cdots$ \\
\hline
\end{tabular}

Notes: Numbers below the diagonal are bias-corrected $\hat{v}^{k}$ for $k=40$, numbers above the diagonal are bias-corrected $\hat{A}^{k}(1)$ for $k=40$. 